E d i t o r i a 1

\title{
Finance and Technology
}

$\mathrm{T}$ hings around us are changing at a pace like never before. Gone are the days when changes in society were influencing business and industry. Today changes in business practices and processes are deciding the destiny of nations. Some of these changes are linear and progressive, whereas most are disruptive. This disruption comes from the path-breaking innovations and their applications in our lives. It is surprising to find how swiftly such innovations are altering the way we live: the way we transact, do business and interact with various stakeholders of our life. Technology has brought multiple changes altering the way our society survived and excelled. More and more application of technology reduces the cost of living, enhances the standard of living, and builds better experiences.

I intend to discuss technological innovation-particularly in the context of transactions, i.e., how we do our financial transactions; how we save, transfer, invest and digitize our net worth. Technology applications in the financial sector have not only created convenience for customers. However, they have led to innovative business models, newer entities, and value-added exchange methods by seamlessly integrating business processes with technological advancements and innovations.

Probably other than war, what matters most in our lives is money; our money guides our extreme sense of survival. If we have plenty- that brings affluence if we have some that help us save for a rainy day, and if we do not have enough makes us work hard and save, and if we fail in saving money, our life is full of despair. Money is so crucial in our life that the very definition of wealth is guided by possessions that we have- though books and scriptures talk about knowledge and spiritual powers as more significant assets.

Money and technology power has always been used to increase its accessibility to more and more people. Technology has helped in the democratization of money in our society. This democratization process of money has made it available to more and more people- hence inclusiveness and more excellent circulation- hence better value creation in the society. Technology has also helped bulk-breaking money into smaller units and

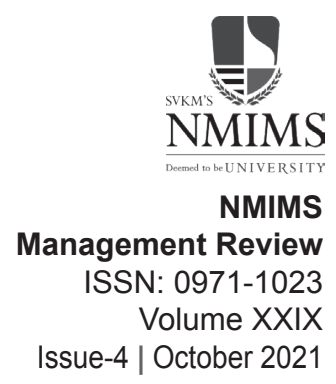


make it available for more inclusive consumption. Let us explore more on the marriage of technology with finance and how the Fintech world emerged over the years.

Companies are working in the area of Fintech we never heard of! We only hear about banks, large financial institutions, and investment bankers whenever we think of money. Such an organized world of money has kept more people away from its embrace. The new generation of technology has brought in more customers who were otherwise outside the ambit of the formal financial sector. A company like EarlySalary offers instant bridge loans till the following salary credit to young working professionals. Buddy, as a company, serves the student community offering then loans for shopping on e-commerce platforms. CapitalFloat helps small and medium enterprises in arranging quick capital for business needs.

These new start-ups are trying to carve out a niche market dominated by larger banks and financial institutions. These companies are leveraging technology and alternate data sources to expand their credit access boundaries and reach out to unserved segments like small and medium enterprises, organized and unorganized sector employees, and micro institutions like self-help groups (SHGs). The other key players in this sector include Indifi Technologies, capital Float, Aye Finance, Origa Leasing, Lending Kart, India Lends, offering easy and quick collateral loans based on consumer transaction data. These loans are between 3 lakhs to 1 crore and are shortterm in nature. The majority operate in the concise term and low ticket category loans (between 15000 INR to 50000 INR).

These companies have emerged in the last few years in India, riding on the government's promotion of cashless technologies like digital wallets, mobile drive point of sales (POS), and the launch of aadhar, e-KYC (Know your customer), UPI and BHIM. Some business-to-business (B2B) areas like credit scoring, authentication have also shown good traction to help the sector grow. Pure play business to consumer (B2C) domain players in payments (PayTM), wealth management, and alternative lending solution providers are fast building scale and profitability.

In the absence of formal data on these new, fragmented customers, Fintech companies use surrogate data from various sources like employee state insurance databases for low-income employees or telephone data for new generation customers to assess their creditworthiness. Companies are using artificial intelligence algorithms to map the lending risk. Companies like Krazybee offers small-ticket loans to students for online products. Gyandhan provides loans to Indian students to pursue higher studies abroad. Redcarpet provides instant loans to students for online purchases, which can be repaid in easy instalments.

NMIMS Management Review ISSN: 0971-1023 Volume XXIX Issue-4 | October 2021

While such a significant change is happening in the Fintech world, what are banks doing? How are they treating the Fintech start-ups - ignoring them, buying them, sponsoring them! These are probably all of these. Banks are either sponsoring them or 
buying out these farms to reach new geographies, new customer segments, and offer new services. Excluding companies like Google with Tez pay, PayTM, and Phone Pe, most of these start-ups are yet to give a big dent in the traditional financial market. It is observed that digital wallets, mobile POS, and P2P lending solutions are the main drivers of growth in the Fintech business.

Players in these segments can provide quicker and more straightforward solutions than formal financial systems and build better customer experiences by automated and contextualized services. Companies use emerging technologies like artificial intelligence, machine learning, and block chain to build better customer experiences and protect their businesses from default risks. Many Fintech players are using chatbots, Robo-advisors for personalized financial planning, and advanced algorithms for fraud detection and prevention of money laundering.

Financial technology is popularly called 'Fintech,' providing technology-enabled financial solutions. This is a marriage between finance and information technology. Interlinkages of finance with technology are not a new phenomenon. The application of information technology to deliver financial solutions has more than a hundred years' history. We can classify them as Fintech 1.0 (1866-1987); Fintech 2.0 (19872008) and Fintech 3.0 (2008- till date).

Fintech 1.0 refers to the first period of financial globalization supported by technological infrastructure like transatlantic transmission lines. Fintech 2.0 refers to financial services firms' increased digitization of processes, and since 2008, Fintech has become globally pervasive with its impact on financial services in both developing and developed worlds. The current generation of the Fintech revolution has given birth to new generation companies challenging the prominent players, market regulators, and policymakers. These companies try to balance between potential benefits of innovation with the possible risk of new service models. We will discuss different eras of Fintech in the following paragraphs.

\section{Fintech 1.0 (1866-1987)}

Finance and technology are interlinked from earlier stages of the development of the financial services industry. The earliest recording of financial transactions dates back to Mesopotamia civilization. The development of money as an intermediary for transactions in financial services has a long history in every civilization. One can see evidence of technology for financial calculations such as the abacus, numbers, and mathematics. This evolutionary development is seen in the context of trade with finance emerging from an early stage to support trade (financing and insuring ships and infrastructures like bridges, rail, roads, and canals) and support the production process of goods for the trade. Double-entry bookkeeping emerged from the intertwined evolution of finance and trade in the late middle age and renaissance. The financial revolution in Europe in late 1600 involving joint-stock companies, insurance, and NMIMS NMIMS

Management Review ISSN: 0971-1023 Volume XXIX Issue-4 | October 2021 
banking played a crucial role in the industrial revolution (1.0). Finance supported the development of technologies that helped industrial development across the world.

Finance and technology were combined in the late 19th century to develop what is popularly known as financial globalization. The same continued till the first world war. Technologies like telegraph, railroads, canals, and steamships, and steam engines helped in financial interlinkages across nations. This led to the rapid transmission of financial information, transactions, and payments across the globe. The financial sector simultaneously provided necessary resources to develop these technologies.

John Maynard Keynes, in his essay The Economic Consequences of the Peace (1920), writes, "The inhabitant of London could order by telephone, sipping his morning tea in bed, the various products of the whole earth, in such quantity as he might see fit, and reasonably expect their early delivery upon his door-step; he could at the same moment and by the same means adventure his wealth in the natural resources and new enterprises of any quarter of the world, and share, without exertion or even trouble."

In his article How Blockchain Tech Will Change Auditing for Good, Matthew Spoke wrote, "Paper is a technology that stores values. The exact size banknote can store INR 10 and INR 50 as long as a state or central bank guarantees the bearer of the note to be paid. Thus the amount printed on the note has theoretically no limit. The Indonesian rupiah is dubious for its million domination notes. Blockchain technology is like a double-entry bookkeeping system. Any transaction processed via the blockchain is registered and sent to the whole network, re-accessing for subsequent auditing. Blockchain accounting is a decentralized process whereby scope for fake transactions are minimized as somebody has to erase the whole Blockchain network, thus removing the scope for financial frauds (Coin Desk, available at http://www. coindesk.com/blockchains-and-the-future-of-audit/)

Financial globalization was constrained for decades due to the world war. On the other side, there were rapid changes in technology, particularly in information and communication technology. IBM (International Business Machines) developed code-breaking tools for commercial applications by creating early-stage computing devices. Texas Instrument developed handheld calculators in 1967. Americans were introduced to credit cards like Diners Club Card, Bank of America, and American Express cards in 1958. This movement was supported by creating the Interbank Card Association (now called MasterCard) in 1966.

By the same period, the world experienced a global telex network providing essential communications for developing the next stage of the Fintech revolution. Xerox introduced the commercial version of the telex called Fax machines in 1964 under the name Long Distance Xerography (LDX). Barclays Bank in the UK introduced the first ATM in 1967.

Management Review ISSN: 0971-1023

Volume XXIX Issue-4 | October 2021

The launch of calculators and ATMs in 1967 is referred to as the modern period of 
Fintech (1967-1987) as that was the time when financial services moved from analogue to digital. The Inter Computer Bureau was established in the UK in 1968, forming the basis of today's Bankers Automated Clearing Services (BACS). US Clearing House Interbank Payments System (CHIPS) was established in 1970. Initially established in 1918, Fedwire became an electronic instead of a telegraphic system in the early 1970s.

SWIFT (Society for Worldwide Interbank Financial telecommunications was established in 1973 to interconnect domestic payment systems across borders. The failure of Herstatt Bank in 1974 highlighted the risk of increasing international financial linkages through payment system technology. So a combination of finance, technology, and regulation constitutes today's USD 5.4 trillion global foreign exchange market which is the most digitized component of the global economy.

The establishment of NASDAQ in 1971 and the end of the fixed securities commission and the eventual development of the National Market System marked the transition from physical trading of securities dating back to $1600 \mathrm{AD}$ to today's full electronic securities trading. Online banking was introduced first in the US in 1980 and in the UK in 1983 by the Nottingham Building Society. Financial institutions increased their IT usage during this period for internal operations, replacing most forms of paper-based mechanisms. They also started using computerized systems to map and manage risk. Michael Bloomberg started Innovation Market Solutions (IMS) in 1981, whereby Bloomberg terminals by financial institutions increased rapidly across the US and Europe. Yang Kaisheng, CEO of the world's largest bank in terms of market share and asset size, writes, "There is a perception that when banks develop internet technology, it is not regarded as Fintech. Some people say this is a new idea, a new ideology that will eliminate agents and intermediaries and that banks cannot adapt

\section{Fintech 2.0 (1987-2008)}

Fintech 2.0 is credited for developing traditional digital financial services. Regulatory attention was rising due to the increased risk of cross-border financial transactions and their interconnectedness with information technology. In the movie Wall Street (1987), the investment banker was flouting a mobile phone for transactions. This year also marked the Black Monday stock market crash, whose effect on the global market reflected the interconnectedness of different national markets through technology.

Though the crash $>$ s reasons are unknown, most people accused the computerized trading system used by financial institutions, which bought and sold stocks automatically based on pre-set programmed price levels. Such a crash led to various mechanisms to control price changes (circuit breakers). Along with the 1982 crisis in developing nations, this crisis brought regulators across nations to cooperate on cross-border transaction issues. The Single European Act (1986) came into effect, establishing a single financial market across the European Union (1992). The UK>s high profile financial liberalization process in 1986, combined with the 1992 Maastricht Treaty

NMIMS

NMIMS

Management Review ISSN: 0971-1023 Volume XXIX Issue-4 | October 2021 
and an ever-increasing number of financial services Directives and Regulations from the late 1980s, set the baseline for the entire interconnection of European Union financial markets by the early 21 st century.

By the late 1980s, the financial service industry turned into a digital industry based on electronic transactions between financial institutions, financial market participants, and customers worldwide under the vigil of regulators. By 1998, the financial services industry had become an entire digital industry. This also gave birth to computerized risk management systems replacing the Long term Capital Management (LTCM) in the wake of the Asian financial crisis of 1997-1998.

Wells Fargo provided online account checking services in 1995, which led to the emergence of the Internet for the next level of technology development. Eight banks across the USA were providing online checking facilities to one million customers in the US by 2001. By 2005, the first direct banks without physical branches emerged, e.g., ING Direct, HSBC Direct. Bank>s internal processes, interactions with outsiders and customers had become entirely digitized by the beginning of the 21 st century. The regulators were using more technology for security exchanges to collect market manipulations. E-banking during this period was simply treated as another channel to serve customers along with branch banking. There emerged a new risk as customers had unlimited access to their accounts without physically being present in the branch for withdrawals. This increased the scope of the liquidity crisis as banks could not forecast necessary cash reserves during transaction periods.

The rapid adoption of online banking increased the probability of credit risk. It was expected that competition would increase due to removing the physical link between consumers and a branch as borrowers would have access to a more incredible list of lenders across geographies. This sounds good from a marketing point of view but was a challenge in bringing financial stability. The structured data collected from various sources were more helpful in understanding the creditor>s profile than a physical acquaintance of the branch manager with the customer. Banks could customize offerings to match the risk profile of customers. Markets, in a sense, could be microsegmented. The use of big data analytics helped in a more granular analysis of consumers profiles and created more diverse market segments. It was expected during Fintech 2.0 that the e-banking would be done only by licensed financial institutions and banks. Fintech 3.0 shows that e-banking is confined to regulated and licensed entities only. The provision of financial services by non-banking institutions led to the regulators having a limited or no role in safeguarding consumers interests.

In a survey in the USA in 2015, it was found that the level of trust Americans have in CitiBank is 37\%, while trust on Amazon and Google are at $71 \%$ and $64 \%$. Amazon and Google are massive, well-established, and well-known organizations. Nevertheless, the reality is that in emerging markets like China and India, there is an increasing 
number of non-listed companies and young start-ups that are handling customers money and financial data. China alone has 20000 P2P lending platforms outside the regulations. People are willing to place or borrow money from these platforms as they are cheaper, give better returns, and are more convenient. The bank name does not make a difference for billions of unbanked people as long as they get the services. They hardly bother about money flowing from or into regulated or unregulated bankers.

\section{Fintech 3.0}

The period from 2009 is for Fintech 3.0, known as the period of democratization of digital financial services. Customer trust in large, regulated financial institutions started dwindling post-2008 global financial crisis, leading to Fintech 3.0. The realignment of market forces supported the emergence of innovative and technology-led financial service providers. This change contributed to public perception, regulatory scrutiny, political demand, and emerging economic conditions.

The financial crisis of 2008 had two significant impacts in terms of public perception and human capital. The public perception of banks went down drastically as their dependence on 'behavioural legacies' (how the customer has behaved in the past) was erroneous. The IT legacy systems were not equipped enough to capture deviations and analyse emerging trends on demand for financial services. The financial crisis was so significant that it became an economic crisis as 8.7 million people in the US lost their jobs. The general public distrusted traditional banking systems, and many financial professionals lost their jobs or settled down with lesser emoluments. This second set of people found a new Fintech 3.0 where they applied their skill, knowledge, and experience, leading to new start-ups in the financial services sector.

Increased regulation in the post-financial crisis led to stricter compliance norms for banks; rejig of commercial incentives and business models. Misuse of financial innovations like collateralized debt obligations was regarded as a contributor to the financial crisis. It detached the credit risk of the underlying loan from the loan originator. Post financial crisis has led to the rise of new technological players limiting the capacity of traditional banks to compete in the marketplace.

The post-crisis regulations gave birth to new technology players as start-ups provided better services to customers. Basel 3 norm expects banks to have increased capital requirements. This norm helped in market stability and greater risk absorbing capacity leading to diversion of funds from private individuals and small and medium enterprises. So these two sets of lenders now have to depend on P2P lending platforms for their credit requirements. Increased unemployment and reduced availability of credit have made the government start new initiatives like Start-Up India, Digital India, Mudra Bank, etc., in India. These are alternative ways to fund businesses through various government-led initiatives.

The Fintech industry has experienced phenomenal growth in the last decade. Global

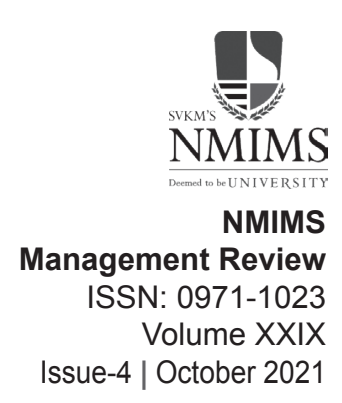


investments in this sector have tripled from 930 million USD in 2008 to 3 billion USD in a decade. The US Fintech industry received $83 \%$ of this investment, leading to technology development for augmenting financial services transactions. The Fintech industry ecosystem can be divided into four verticals (1) digital and electronic currency, (2) digital payment systems, (3) online finances and investment platforms, and (4) big data analytics. Each of these verticals has experienced significant growth in the past decade due to advances in technology, rapid consumer adoption, changing investor and consumer preferences, a shift in the regulatory landscape, and renewed efforts via mobile banking.

More than 200 digital currencies exist, out of which 12 have a market capitalization of more than 5 million USD. Digital currencies drive financial disintermediation and offer newer P2P (peer-to-peer) channels for routing payments, both in domestic and international markets. More than 63000 merchants were accepting bitcoins, with 5.3 million bitcoin wallets in existence, up from 765000 a year ago. Volatility in prices is the primary source of significant users $>$ uneasiness, security concerns, and regulatory uncertainty. Electronic currencies are bringing greater financial inclusion. In Africa, the most popular one is M-Pesa, a mobile account system launched in 2007 in Kenya. Venmo in the US processed 468 million USD in peer-to-peer payments. PayTM in with its digital currency wallet, is a success story in India. Like virtual currency, electronic currency is converging into the next Fintech vertical- digital payments- by enabling transactions that fall outside the traditional payment system.

Digital payment systems continue to evolve and transform the way consumers transact with business. The Rupay, Phonepay are examples of digital payment systems in India. Both Apple and Google have also launched their Apply pay and Google pay systems which are additional mobile payment service providers disrupting the payment marketplace. Companies like Square and PayPal are experiencing significant growth in their business, where PayPal transacts around USD 7000 in payments every second. These two companies, backed by data analytics, are entering into small business lending markets by providing customized loans. Innovations in communicating payment, ensuring security in transactions are changing the digital payment landscape. The intelligent chip payment technologies used by EMV (Europay, Mastercard, and Visa) are driving the old POS (point of sale terminals). NFC (near field communication) technologies allow mobile devices to communicate payments by placing devices within proximity of each other.

Online finance and investment platforms are the famous faces of the Fintech industry. They challenge traditional financial services providers with low-cost, efficient, and user-friendly products and services. Companies like Wealthfront, Betterment, and Acronis create automated financial advisory platforms. Peer to Peer lenders like Lending Club, Prosper, and Sofi are lending to individuals, whereas online marketplace lenders like FundingCircle, OnDeck, and Kabbage lend to small enterprises. 
As more and more transactions take place on digital platforms, there will be massive data available for credit risk analysis and predicting demands. Massive data aggregation and analytical tools are helping financial services platforms and service providers to offer low-cost, innovative products and services. Companies are developing credit risk models with multi-attribute dashboards to ascertain the credit risk; to develop real-time innovative products and services and service customers without much delay. Algorithm-based trading practices rely on complex aggregation and analytics. The rising role of data is building a challenge, including cybersecurity, personal privacy, data theft, and insider trading.

\section{Fintech Industry: Topological Brief}

Today $>$ S Fintech industry consists of five areas, namely finance and investment, operations and risk management, payments and infrastructure, data security and monetization, and customer interface.

Much of the discussion today in the area of Fintech revolves around finance and investment as both public and regulators> attention is quickly drawn into managing alternative financing mechanisms, particularly crowdfunding and P2P lending. However, Fintech goes beyond these two domains. It includes financing technology itself through venture capital investment, private equity, private placements, public listings, and other newer funding methods. The future investments in Fintech are in emerging areas like high-frequency trading, dark pools, and Robo advisory services.

Financial Institutions have invested heavily in IT-enabled financial and risk management systems since 2008. The industry has built robust systems based on VaR and other risk management systems to optimize profits. The effort is backed by research in financial services and the application of quantitative finance in predicting service expectations and returns from consumer segments.

Mobile phone-based banking and Internet-enabled banking transactions are becoming the industry standards. This has led financial services companies to invest in developing apps and payment gateways via the Internet and mobile in most developing countries. Increased growth in cross-border electronic payment systems has led to a string of USD 5.4 trillion per day global foreign exchange market. Infrastructure for securities trading and settlements and derivatives trading have also invited heavy investments and built a healthy market in the Fintech landscape. These are enabled through IT applications and developing automated transaction systems. IT and telecom companies are exploring opportunities in this space to disintermediate traditional financial institutions.

While changes in IT-enabled communication have driven people into the Fintech industry and provided convenience for transactions, data security and monetization have remained an area of concern and opportunity for deriving the monetary value of data. The more we digitize financial transactions, the more significant is the

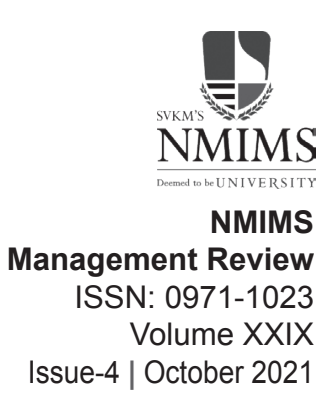


risk of cybercrime and espionage. This will be a primary concern for government, policymakers, regulators, and industry participants. The Fintech industry looks up to <big data to enhance security and reduce the scope for cybercrime.

The Fintech industry is trying to make the consumer interface as authentic as possible through online and mobile financial services through personalization, convenience, and greater interactivity. IT and mobile technology companies compete directly with traditional financial services players in this space. The focus of emerging and established financial services players, IT companies, and mobile communication companies are on the developing countries where the volume is enormous and traditional banking is not that well developed. The later companies hold an advantage over traditional financial services companies in this domain. They have a massive database of existing customers targeted with innovative financial products and services.

\section{Fintech 3.0 in Developing Countries}

Fintech 3.0 emerged in the developing nations as an outgrowth of economic development as more and more people seek access to capital and other financial services. Countries like India and China have undergone massive economic reforms and have allowed private financial services providers, including private banks and NBFCs, to grow. One can credit the growth of the Fintech industry to the emerging megatrends.

India has moved from state-owned banking models to licensed-based private and public banking models. India boasts of one-third of the younger population of the world who are digitally savvy and are equipped with mobile devices. There exists an inefficient and scam-driven capital market-creating opportunity for informal alternatives. The country lacks physical banking infrastructure in remote rural areas; there is a high behavioral pre-disposition favoring convenience over trust in the rural heartland. $65 \%$ of Indians live in rural areas far away from regular banking practices, an untapped market. The government has initiated (a) direct benefit transfer (DBT), eliminating unscrupulous financial intermediaries, and (b) Jan Dhan Yojna for welfare benefits passed on to citizens through the banking system leading to the massive demand for capital and financial services. India is less stringent on data protection and competition, leading to a quick turnaround model for the growth of Fintech players and alternative offerings. The dynamic private sector is also interested in entering into the financial services business, which can drive economic growth in India. The Fintech industry's growth in China and India is not due to the financial crisis of 2008 but is fueled by entrepreneurial and economic growth.

However, the picture is not that rosy as it seems. Investors in this space are less sophisticated and risk-averse compared to developed nations. The level of information asymmetry and market dysfunctionality is comparatively high in emerging markets like India. There is a high barrier to entry in the retail banking space in India due 
to the more important requirement of regulatory capital, ownership structure, and market restrictions. Technically financial engineering is also at an early growth stage in markets like India. Since the savings are more petite and people prefer security over a return, Robo advisory platforms on wealth management are not able to achieve a scale through the creation of a «micro- portfolio〉 by using sophisticated algorithms.

Developments in the Fintech industry highlight that financial services can be democratized further. Africa provides a more significant opportunity than Asia as only $20 \%$ population has access to formal or some form of financial services compared to $60 \%$ in Asia. Telecommunication companies have taken the lead in the Fintech space in Africa through innovative products and services. Fintech players in countries like the Philippines, Kenya, and Tanzania can create mobile money wallets for actual payments and savings services. The mobile money revolution has assisted in significant economic development by providing customers with a means to save, remit money safely, pay bills and receive government benefits in a safe and secured manner.

M-Pesa is the most successful story in Africa, launched by Vodafone in 2007. In five years, the payments made through this platform have gone above $43 \%$ of the GDP of Kenya. The learning lesson from M-Pesa is that digital financial services will only succeed when it addresses the local needs of customers. The Fintech industry in Africa consists of provisions for a mobile wallet for allowing payments and savings and, of late, have entered into credit and micro-insurance. The mobile telephony companies in Africa encourage customers to purchase e-money and airtime on their mobile phones at the same place and the same way by paying cash to a retail agent who is typically a Kirana store selling snacks, soft drinks, and household goods along with airtime. The significant difference between Fintech 2.0 and Fintech 3.0 is the type of entity that uses technology to deliver financial products and services to customers. Fintech 3.0 has created a level playing field.

\section{Regulation in Fintech Industry}

The traditional financial services sector is a well-regulated industry with financial institutions, regulators, and a central bank working under a defined regulatory framework. The Fintech 3.0 start-up companies are entering the financial services business with limited or non-existent regulation. The new entities lack a culture of regulatory compliance, bringing in issues related to consumer protection and obligations in delivering services to consumers. Some existing regulations may not work for these non-traditional companies, particularly IT and mobile communication companies. So what laws and regulations should be applied to these emerging companies? The regulation should balance these three players: the technology player, the financial actors, and the regulators.

Regulations in this sector should not be prohibitive, thus limiting the growth and not being predatory to kill the start-ups. The regulations should focus on (a) financial 
stability, (b) prudential and futuristic legislation, (c) conduct based on equity and fairness, and (d) completion and market development. One should also note that technology needs time to find its final usage and applicability, and a market needs to mature before regulators intervene. A premature regulation may otherwise hamper the growth of some evolving entities. This has happened in the US, where e-banking was introduced in the 1980s and then stopped before emerging again in 1995.

Rita McGrath (2013), in her article «The Pace of Technology Adoption is speeding up,» mentions that it took decades for the telephone to reach $50 \%$ of the customers in the US; five years or less for mobile phones to achieve the same level of penetration. The laser technology also took a long time to be adopted by the public for various industries, including fingerprinting and iris scanning, voice, and heartbeat recognition. Innovations in Fintech 3.0 are emerging out of sandboxes, incubators, and accelerators, with each player refining the solutions over some time. So these technologies need time for regulation. Money market funds were established way back by prominent players like Vanguard (1975), Fidelity (1946), and Schwab (1971), respectively, but in 2014 Alibaba in China started to offer a new and purely online money market fund to its pre-existing customers. Within nine months of its launch, $\mathrm{Yu}$. E Bao became the world $>$ s 4th largest money market fund. This shows how a non-traditional financial institution grew from 〈too small to notice〉 to 〈too big to fail.〉

\section{Regulations in the Digital Age}

We can conclude from the above discussion that we need to wait for the Fintech 3.0 industry to mature before regulations are brought in like any other technologyled industry. What matters most is how regulations are brought and how they are managed. There is a greater need to bring in an attitudinal change towards regulations and a move from regulating the prominent, established players to developing a level playing field for small, emerging players. The financial services industry consists of large established financial institutions and emerging start-ups.

With the high cost of regulations in compliance, license applications are challenging for a start-up to match up as they work on a lean business model. The primary focus is on developing suitable products and services with business potential rather than large outlays for compliance norms. One should implement spirit-based rather than 'box ticking' regulations. This is called a principle-based regime (then a rule-based regime). The rule-based regime creates clear rules and processes and expects players to comply. This approach is expensive for a start-up as these rules and processes may consume financial resources that could have been used for innovation.

The regulatory environment should be more dynamic and adaptable to the size and activities during its period of growth and changes. For example, P2P lending is based on a business model where the platform allows agents to introduce lenders to borrowers and are not involved in the loan itself. This does not require too many regulatory obligations 
as it matches the liquidity of a lender and the demand of a borrower. This limits the scope of increasing the scale of operation for the start-up. This also exposes the lender to the direct credit risk of the borrower. The platform plays the role of an 'agent' (not the 'principal') and is not responsible for any losses resulting from defaults.

This eventual shift in risk towards the lender has two eventualities (a) increased number of lenders losing their capital as a result of poorly evaluated risk rising to loss of confidence on the platform and (b) the risk profile of such a liquidity placement on a P2P platform is much higher as it is passed directly to the lender. These factors will limit the number of potential lenders on the platform as increased return leads to a proportional increase in risk. So P2P platforms should move from purely agent-based models to principal-based models. The platform itself can spread the borrower $>\mathrm{s}$ credit risk by originating a loan using the liquidity of different lenders. Ease of borrowing in terms of convenience and speed and lack of coordination among platforms also increases the risk of over-indebtedness among borrowers. Over 1250 platforms in China have been flagged «at-risk» by the local credit rating agency Dagong.

\section{Data-led Regulatory Framework}

Fintech 3.0 should bring in a balanced regulatory framework protecting the interest of all three stakeholders, namely technology players, financial institutions, and regulators. Since information technology-led transactions generate a tremendous amount of transaction data, there can be a data-led regulatory framework where insights from data can be used for regulation. This method will help in future market development by maintaining financial stability.

Regulators should move towards a risk-based approach where access to data is key to prudential supervision. Greater compliance has led to cost increases for financial institutions regarding capital (e.g., Basel 3), operations (e.g., technologically qualified human resources), or penalties for no compliance. The Fintech 3.0 players can use (a) pattern analysis to identify unusual patterns of activity and take precautionary measures for the same to avoid any fraudulent activities (b) big data analytics, which uses external data along with transaction data and develops insights by using a more significant number of inputs to link silos of data and give meaningful insights by using algorithms that can identify a broader range of suspicious activity than just developing patterns (c) predictive coding which helps in identifying pattern of activity such as an unusual set of communication, the non-routine pattern of behaviour and conducts and (d) digitization of voice communications which has the potential to be more effective than written communication. Real-time compliance by using technology will help reduce risks related to solvency leading to market stability.

\section{Conclusion}

The current era of Fintech 3.0 is a culmination of diversity and is based on a philosophy of democratizing access to finance through technology. Universalization of financial 
resources and providing access to financial resources through alternative finances can bring a more unbankable population into its fold. The financial services industry is highly regulated, like the pharmaceutical industry. However, this critical sector impacts economic growth across the globe. Critical players' fraudulent activities and scams have often led to global financial crises despite so many regulations.

The emergence of Fintech 3.0 across the globe brings two exciting findings. The Fintech industry 3.0 grew in developed markets due to the global financial crisis of 2008 based on public expectations and demands. In contrast, the same in developing countries is credited to economic growth and demand for capital and financial services by people who were otherwise outside the purview of banking and financial services. Inefficiency in the system, asymmetry of information, and existing dysfunctionality in the market have given birth to Fintech 3.0 in most developing nations.

Fintech 1.0 and 2.0 were all about applying information technology in digitizing the business processes or providing online services by established players in the banking and financial services sector. Internet-based technology and mobile communicationbased technological innovations have led to the entry of new players in Fintech 3.0 who are small but able to deliver services better than the traditional financial services players, particularly to segments that large financial institutions did not serve through innovative product and service offerings.

Fintech 3.0 brings three prominent stakeholders to the forefront: technology startups, financial institutions, and regulators. Many large financial institutions have bought over the technology start-ups. They have included them as their service offerings, whereas some innovative products have remained unique players. P2 P lending platforms are more successful as they have brought lenders with liquidity and borrowers with demand to a common platform for the transaction. However, these agent-based models have increased the risk levels for lenders as erroneous credit scoring can increase the risk of default in lending.

As discussed, regulators are watching closely how this industry is shaping up. There is a growing debate to allow the Fintech 3.0 industry to mature before legislation is brought in. This is primarily because regulation will bring in capital adequacy, processes and operations, and risk management compliance. Start-ups need to build the business using the available investments rather than engaging in a costly compliance process. Since Fintech 3.0 is in an evolutionary process in terms of innovations in product and service offerings, the players and industry will undergo multiple rejigs. So the regulator should wait and watch before bringing in norms and legislations.

The regulations should be more principle-based than rule-based facilitating market development and access. A conversation is going on about tech-enabled regulations by using data-driven approaches. Fintech 3.0 players should use transaction data to identify patterns, analyse big data with additional data inputs, and use predictive 
modelling to map the credit risk and build market development strategies. The challenge is to balance a flexible, forward-looking framework promoting product and service innovation to cater to customer needs and clear enough guidelines to maintain the market, consumer, and investor confidence.

Regulators in developed nations, including the UK, have changed the structure from a product-based to a principle-based approach, focusing on prudential regulation and consumer protection. Developing markets like India and China have maintained product-based principles and gradually introduced a two-tiered system where startups and internet/mobile finance companies can handle small to medium transactions. In contrast, more significant transactions remain in the remit of large financial institutions.

\section{Dr Tapan K Panda}

Editor in Chief

\section{References}

- Arner, D. W., Barberis, J., \& Buckley, R. P. (2015). The evolution of Fintech: A new post-crisis paradigm. Georgetown Journal of International Law, 47(04), 1271-1320.

- Kelly, G. (2014). The digital revolution in banking. Occasional Paper 89, 1-52. https:// citeseerx.ist.psu.edu/viewdoc/download?doi=10.1.1.697.1966\&rep=rep1\&type=pdf

- Brummer, C. (2015). Disruptive technology and securities regulation. Fordham L. Rev., 84, 977-1052. https://ir.lawnet.fordham.edu/flr/vol84/iss3/6

- Brummer, C., \& Gorfine, D. (2014). FinTech: Building a 21st-century regulator's toolkit. Milken Institute working paper, 1-14. https://milkeninstitute.org/sites/default/ files/reports-pdf/3.14-FinTech-Reg-Toolkit-NEW_2.pdf

- ICBC Chairman welcomes Fintech Reg, Finance Asia, available at http://www. financeasia.com/News/400732,icbc-chairman-welcomes-Fintech-regs.aspx retrieved on 01-12-2021. As an example, approximately 33000 staff working at Goldman Sachs are engineers, more than LinkedIn, Twitter, or Facebook.

- Arner, D. (2016). FinTech: Evolution and regulation. Presentation Slides, June. 1-33. https://law.unimelb.edu.au/_data/assets/pdf_file/0011/1978256/D-Arner-FinTechEvolution-Melbourne-June-2016.pdf

- Arner, D. W., Barberis, J., \& Buckley, R. P. (2016). 150 years of Fintech: An evolutionary analysis. Jassa, (3), 22-29. https://search.informit.org/doi/10.3316/ ielapa.419780653701585

- Singh, Rantej (2016, September 16). How startups are leading innovation in Fintech 3.0. Vccircle. https://www.vccircle.com/how-startups-are-leading-innovationfintech-30

ORCID Id: https://orcid.org/0000-0001-9005-3031 